\title{
Cardiovascular events and additional risk in hypertensive senior citizens
}

\author{
Eventos cardiovasculares e risco adicional em idosos hipertensos \\ Eventos cardiovasculares y riesgo adicional en ancianos hipertensos
}

Rosimeire Fontes de Queiroz ${ }^{1}$, Ângela Maria Alvarez², Alacoque Lorenzini Erdmann², Amanda Louise de Medeiros França ${ }^{1}$, Cláudia Bezerra de Souza Pereira ${ }^{3}$

The research aimed to investigate cardiovascular events and additional risks in hypertensive senior citizens' files attended in a Family Health Unit in Natal/RN, Brazil. This is a descriptive and documentary study developed based on 106 files from the Hiperdia Program registered from August to December 2012. The results showed that $13.2 \%$ were victims of Stroke, $10.37 \%$ of Acute Myocardial Infarction and $8.4 \%$ of other coronary diseases. In the cardiovascular risk stratification, $68.86 \%$ did not show additional risks, $31.11 \%$ were classified from low to very high risk for cardiovascular diseases. The results allow the planning of actions to take care of hypertensive senior citizens and are worthy of consideration for the Nursing professional practice, especially regarding the reorganization of its working process avoiding possible events.

Descriptors: Aged; Hypertension; Cardiovascular Diseases; Health Promotion.

A pesquisa teve como objetivo investigar eventos cardiovasculares e risco adicional em fichas de idosos hipertensos acompanhados numa Unidade de Saúde da Família em Natal/RN, Brasil. Estudo descritivo e documental desenvolvido com base em 106 fichas do Programa Hiperdia cadastradas no período de agosto a dezembro de 2012. Os resultados indicam que 13,2\% foram vítima de Acidente Vascular Encefálico, 10,37\%, de Infarto Agudo do Miocárdio e 8,4\% de outras coronariopatias. Na estratificação do risco cardiovascular, 68,86\% não apresentaram risco adicional, 31,11\% foram classificados em baixo a muito alto para doença cardiovascular. Os resultados subsidiam o planejamento de ações destinadas a cuidar dos idosos hipertensos e são dignos de reflexão para a prática profissional da enfermagem, principalmente no que se refere à reorganização do seu processo de trabalho evitando possíveis eventos.

Descritores: Idoso; Hipertensão; Doenças Cardiovasculares; Promoção da Saúde.

El objetivo de la investigación fue investigar eventos cardiovasculares y riesgo adicional en fichas de ancianos hipertensos acompañados en una Unidad de Salud de la Familia en Natal/RN, Brasil. Estudio descriptivo y documental con desarrollo basado en 106 fichas del programa Hiperdia registrados de agosto a diciembre de 2012. Los resultados señalaron que 13,2\% eran víctimas de accidente cerebrovascular, $10,37 \%$ de infarto agudo de miocardio y $8,4 \%$ de otras enfermedades coronarias. En la estratificación del riesgo cardiovascular, 68,86\% no presentaron riesgo adicional, 31,11\% fueron clasificados en baja a mucho alto riesgo para enfermedad cardiovascular. Los resultados proporcionan la planificación de acciones para cuidar de ancianos hipertensos y son dignos reflejo para el ejercicio profesional de la enfermería, especialmente en relación con la reorganización del proceso de trabajo para evitar posibles eventos.

Descriptores: Anciano; Hipertensión; Enfermedades Cardiovasculares; Promoción de la Salud.

\footnotetext{
${ }^{1}$ Universidade Federal do Rio Grande do Norte. Florianópolis, SC, Brazil.

${ }^{2}$ Universidade Federal de Santa Catarina, Florianópolis, SC, Brazil.

${ }^{3}$ Programa Saúde da Família do Município de Natal. Natal, RN, Brazil.

Corresponding author: Rosimeire Fontes de Queiroz

Av. Maria Lacerda Montenegro, 515, Residencial Panamericano, Torre I, Apto 704, Nova Parnamirim, Parnamirim, RN, Brazil. CEP: 59.152600. E-mail: roseerai@hotmail.com.
} 


\section{Introduction}

In the search for an active aging it is essential a careful observation of the growth of the elderly population in the country and, allied to this situation, the increased demand for health services in primary care focused on this segment. In this sense, the identification of hypertension in the elderly and the establishment of a bond between them and the professionals of the Family Health Strategy (FHS) are necessary to control this disease successfully ${ }^{(1)}$.

High blood pressure (HBP) is a serious public health problem in Brazil, affecting around $20 \%$ of the adult population. That means there are approximately 20 million people with hypertension in the country. The prevalence of primary systemic hypertension varies from $5 \%$ in the population from 18 to 24 years old to $58 \%$ in the population over 65 years old. The mortality analysis indicates that the three main causes of death in our country are, in order: acute myocardial infarction, stroke and heart failure, all related to the hypertension risk factor ${ }^{(1)}$.

Mortality rates due to hypertension have remained stable in recent years, around 150 deaths per one hundred thousand people in the population who are more than 60 years old and 20 deaths per one hundred thousand people in the population from 40 to 59 years old. Stroke's death rate has stabilized since 2001, around 45 deaths per one hundred thousand inhabitants, and the mortality rate for acute myocardial infarction in about 35 deaths per one hundred thousand inhabitants. Regarding hospital morbidity, out of the ten main causes of hospitalization in the Unified Health System, four of them occur from cardiovascular diseases: heart failure, 4.3\%, stroke, 1.9\%; acute heart failure, $1.0 \%$ and hypertensive crisis ${ }^{(1)}$.

The continuous monitoring of hypertensive senior citizens may prevent the appearance and progression of complications, reducing hospital admissions and mortality associated with these conditions. The elderly's needs, such as difficulty in memorizing and auditory and visual deficits, associated with low education, require from nurses specific skills to take care of this age group, considering the elderly's low adherence to the antihypertensive treatment. The importance of nurses' role in this context is indisputable, so it is their duty to preserve and maintain the functional capacity of the elderly, provide family care guidelines about the illness conditions of the aged person during home visits and about disease prevention ${ }^{(2)}$.

The increasing incidence of cardiovascular diseases is an important consequence of the aging of the world population and it is the main cause of death among the elderly. The presence of hypertension and diabetes in this age group deserves attention because of the greater vulnerability they have when cardiovascular and cerebrovascular complications are associated with clinical conditions and other risk factors that accumulate over time ${ }^{(3)}$. However, this serious health impairment can be reversed through interventions on disease prevention and health promotion and recovery, reducing the chances of risk of undesirable events with monitoring and detection of hypertension, preventing complications and initiating timely treatment.

The main determinants of the increase in chronic conditions are demographic changes, changes in consumption patterns and lifestyles, rapid urbanization and marketing strategies. Changes in consumption patterns reflect in behavior and lifestyle. Unhealthy habits crystallize and increase chronic conditions, such as smoking, excessive alcohol consumption, unsafe sex, physical inactivity, excess weight, unhealthy diet, and social stress ${ }^{(4)}$.

In this sense, the health promotion practices can be understood as strategies that assist individuals and the community to develop skills that are necessary for their survival ${ }^{(5)}$. Thus a senior citizen should be seen as a fundamental agent in the construction of knowledge and practices that can meet their needs and develop their potential. Therefore, the nurse's role as a member of the interdisciplinary team is to recognize in the elderly with risk factors the ability to restore their health and take care of themselves. 
As a response to the challenge of combating Chronic Non-communicable Diseases (NCDs), the Brazilian Ministry of Health has implemented important policies to battle them, especially the Organization of Surveillance of NCDs, whose goal is to understand the distribution, magnitude and tendency of chronic diseases and injuries with their risk factors, supporting public policies to promote health ${ }^{(6)}$.

The National Policy of Health Promotion (NPHP), published in 2006, prioritizes several government actions in the field of healthy eating, physical activity and prevention of tobacco and alcohol use. The program Health Gym, created in April 2011, aims to promote physical activity and has as its goal to be extended to four thousand cities until 2015, including disease prevention and health promotion as a priority in the country's health policy ${ }^{(6)}$.

The educational activity is one of NPHP's guidelines through which empowerment and social participation should lead people to choose transforming paths that point to values of justice and solidarity, productivity and equity, being equivalent to a process of power development and search for their rights to achieve improved quality of life ${ }^{(7)}$.

When nurses develop actions of health education they are aware that education is not restricted to collective actions, but they also occur at an individual level with the aim of educating people with active citizenship and of transforming their social reality; it seeks to improve quality of life, not only worrying about the communication of information, but also fostering motivation, skills and confidence necessary for people to improve their own health and their community's by increasing their knowledge, skills and critical awareness.

One of the strategies that the nursing staff can use to promote health is a constant dialogue with social movements, establishing ways of more permanent and sustainable connection, allowing the multiplication of solutions for health problems ${ }^{(8)}$. Actions must assume that individuals are able and have the potential to deal with their health problems in a healthy way, making them empowered.
Empowerment enables the learning of a greater personal independence and the adoption of healthier lifestyles, which might improve the relationship between people and their social environment. However, in order to reach that goal, it is essential the promotion of health education, which is considered a major step to promote the empowerment of people to whom health actions are directed ${ }^{(9)}$.

It can be added to the previous reflection, that there is a lot of discussion about dialogue and professional-patient relationship, which often cannot be achieved due to health professionals' attitudes, who are not always able to welcome and conduct an active listening, triggering a negative rebound in the continuity of treatment ${ }^{(9)}$. Given the above, there is room for the question: what are the cardiovascular events and additional risks in hypertensive old patients attended at a Family Health Unit in Natal?

To answer this question, one aimed to investigate cardiovascular events and additional risk in hypertensive senior citizens attended at a Family Health Unit (FHU) in Natal/RN, Brazil.

\section{Method}

Documentary, quantitative study ${ }^{(10)}$, conducted from August to December 2012 in a Family Health Unit in Natal/RN, Brazil, located in a district of West Natal, which has four health teams, however the survey was conducted with only one of the four teams.

The documentary study allows the researcher to describe and understand the content of documents, in order to answer his question by describing and analyzing them. Document analysis is represented by authentic documents, called primary sources; in the case of this study, the sample consisted of 106 senior citizens registered at the Hiperdia program from the FHU.

Updated and completely filled records were used as inclusion criteria. This consists of demographic data (age, gender, race, family/marital status, education), clinical (blood pressure, BMI, waist circumference, risk factors and concomitant diseases, cardiovascular family history, diabetes, smoking, physicalinactivity, overweight/ 
obesity, hypertension, presence of complications of acute myocardial infarction, other coronary artery diseases, stroke, diabetic foot, amputation due to diabetes, kidney disease), and characterization of treatment (type of treatment, number of daily medication, insulin, use of other drugs).

The blood pressure values were the ones recorded in the registration form, measured and classified at the moment of registration according to the VI Brazilian Guidelines on Hypertension 2010. To assess the additional risk of the elderly were considered in addition to blood pressure values, the presence of risk factors, damage in target organs and cardiovascular diseases recorded in the entries investigated. Descriptively analyzed, the results were organized in tables and graphs. To characterize the population and organize the data, the software Statistical Package for Social Sciences (SPSS) version 15.0 was used. The research project was submitted to the Ethics Committee in Research of the Universidade Federal do Rio Grande do Norte (UFRN), which approved it with the Opinion 122047/2012.

\section{Results}

The results show that out of 106 records investigated from hypertensive senior citizens, $66.1 \%$ were females and $33.9 \%$ males, which characterized a greater involvement of women. Regarding education, the majority of the hypertensive senior citizens are literate $(73.5 \%)$, out of these only $36.8 \%$ can read and write and $35.8 \%$ had the opportunity to get to elementary school or high school.

Table 1 - Sociodemographic characteristics of hypertensive old patients registered at the Hiperdia program

\begin{tabular}{lc}
\hline Sociodemographic characteristics & n (\%) \\
\hline Cannot read or write & $28(26.5)$ \\
Literate & $39(36.8)$ \\
Elementary or high school (incomplete or complete) & $38(35.8)$ \\
Higher education (complete or incomplete) or more & $1(0.9)$ \\
\hline
\end{tabular}

Table 2 shows that $68.9 \%$ of the hypertensive senior citizens have high blood pressure ranging from great (SBP $<120$ and DBP $<80 \mathrm{mmHg}$ ) to borderline (SBP 130-139 and DBP 85-89 mmHg) with therapeutic control using medication or not, but still requiring attention.

Table 2 - Classification of the elderly as to their blood pressure levels

\begin{tabular}{lc}
\hline Blood Pressure & n (\%) \\
\hline Great & $35(33.0)$ \\
Normal & $8(7.5)$ \\
Borderline & $30(28.4)$ \\
Stage 1 hypertension & $17(16.0)$ \\
Stage 2 hypertension & $9(8.5)$ \\
Stage 3 hypertension & $7(6.6)$ \\
\hline
\end{tabular}

The diseases that affect the circulatory system were among the main injuries in target organs, being the cerebrovascular accident the first, with $13.2 \%$, the Acute Myocardial Infarction, with $10.37 \%$ the second and the coronary heart disease the third, with $8.4 \%$.

Regarding cardiovascular risk, according to the information from the elderly's records, 68.9\% had no risk, while 14 (13.3\%) had very high risk, 11 (10.4\%) medium risk and 6 (5.6\%) high risk. The cardiovascular risk was low in $2(1.8 \%)$ of the elderly.

\section{Discussion}

There was a predominance of females corroborating the results found in studies conducted in Fortaleza, Ceará, Brazil, in which out of the total participants, $69.2 \%$ were females and $30.8 \%$ males $^{(2)}$. According to the VI Brazilian Guidelines on Hypertension $^{(11)}$, the overall prevalence of hypertension between men and women is similar, although it is higher in younger men up to 50 years old. However, this condition is reversed from that age on, as highlighted by that guideline.

Women look more often for health care than 
men. On the other hand, the small male clientele in health services is composed by the elderly who take this initiative driven by a chronic disease, such as hypertension and diabetes, in search of consultations, prescriptions or free medication $^{(12)}$.

As for education, in the study conducted in Fortaleza, Ceará, Brazil, $88.5 \%$ had low education and not completed elementary education ${ }^{(2)}$. The level of education influences directly the uptake of guidelines about the pathology, so the lower the education the more difficult it is to understand the diagnosis, change of habits and adherence to dosing schedules, inferring that there is a relationship between formal education and treatment adherence ${ }^{(13)}$. In contrast to this statement, it is emphasized that the work of education developed in open universities for senior citizens' education advocates for the elderly based on the concept of lifelong education and reaffirms the requirement of the use of appropriate teaching methodologies in all stages of human life.

The current concept of lifelong education eliminates the traditional distinction between initial formal education and lifelong learning, converging towards another concept frequently proposed: the educational society in which everything can be an opportunity to learn and develop talents ${ }^{(14)}$.

The lifelong education must open the possibilities of education for everyone, with several goals: offer a second or a third chance, meet the thirst for knowledge, beauty or overcoming oneself; or even enhance and expand trainings associated strictly with the requirements of professional life, including practical training. In short, they should take advantage of all the opportunities offered by society ${ }^{(14)}$. The educational activity should encourage people to choose to transform paths with values of justice and solidarity, productivity and equity, being equivalent, therefore, to a process of development to pursue their rights and achieve improved quality of life ${ }^{(7)}$.

Although the number of participants with great, normal and borderline figures are higher, it is still big the frequency of old hypertensive patients with uncontrolled blood pressure because when analyzing pressure values, according to the classification of the VI Brazilian Guidelines on Hypertension, were highlighted in the study the sum of $31.1 \%$ of cases with pressure outside normal limits. This situation characterizes real predisposing factor for cardiac, cerebrovascular and renal diseases, contributing to increased cardiovascular mortality and affect directly the quality of life and longevity of the elderly. Considering this fact, the practice of nursing care should be strengthened in the continuous monitoring of the old people.

The stroke is the leading cause of hospitalization, mortality and dysfunction, and hypertension is the main risk factor for developing it; however when blood pressure is controlled, the risk of stroke falls up to seven times ${ }^{(15)}$.

In the Brazilian population, numbers from Datasus show almost 650,000 deaths in individuals over 60 years old in 2007. Out of this total, about 230,000 are due to circulatory diseases, 66,000 due to ischemic heart disease and 75,000 due to cerebrovascular diseases, conditions closely related to hypertension ${ }^{(16)}$.

Hypertension complications should be postponed to the maximum so that addiction, especially physical, and disabilities manifested by the elderly are only those resulting from aging itself, to which the elderly adapts easily, and not those that harm their daily life activities ${ }^{(17)}$.

Fundamental subject on the implementation of public health policies and playing a relevant role in the family health strategy, Nursing should incorporate into its professional practice activities to promote health and control of NCDs, considering them as part of health care. However, coping with NCDs also requires efforts of the health sector and other sectors, due to the magnitude and complexity of their determinants ${ }^{(6)}$.

The actions of health promotion are essential and aim at the universal protection, the health communication and intersectoral action, among others. The regulation is essential in the NCDs Plan, 
and several measures adopted include intersectoral coordination, involving topics such as alcohol, tobacco and food, which require integration between government, legislature and society, on the definition of the measures that can cover more people, as the regulation of food advertising, banning tobacco and alcohol advertising and banning alcoholic beverages to minors, among others ${ }^{(6)}$.

When assessing the additional cardiovascular risk, it was found that $68.86 \%$ of the elderly do not have it, but even so, they should be kept under surveillance and treatment that may not fit in another moment in the global score, avoiding an unwanted cardiac event. However, $31.11 \%$ were classified into risk condition ranging from low risk and very high risk for cardiovascular disease. The very high-risk patients are those with some prior events, and must remain vigilant, due to the probability to have it again. These results encourage reflection on the need to implement the proposals of health policies to attend the elderly in the context of the UHS aiming at prevention actions through health education that addresses the old people as individuals capable of taking care of their health.

These results differ from studies conducted in another context, a study conducted in Fortaleza in 2009 , in which $35.8 \%$ of the elderly presented additional medium risk and 35\% additional high risk for cardiovascular diseases. It is noticed that the subjects of the present study show lower values, assuming that they have better health conditions ${ }^{(18)}$.

The pharmacological and nonpharmacological treatment should aim not only at blood pressure reduction, but decrease the cardiovascular morbidity and mortality ${ }^{(19)}$. Given this reality, it becomes evident the role of family health professionals, in particular nurses, who must understand the nature of these diseases and associated risk factors for planning control strategies and monitoring of this age group. It is essential the development of promotion and education activities throughout life so that the elderly can prevent health problems and possible sequelae ${ }^{(2)}$.

In this sense, if nurses take up the role of educators, they may influence effectively in the elderly's behavior, promoting changes in the risk factors for high blood pressure, thus preventing cardiovascular complications.

As a limitation of this research one highlights the use of secondary data, as these were often difficult to interpret because of problems in filling in the registration form such as unreadable data or incomplete information.

\section{Conclusion}

The results showed that the elderly who participated in the study were victims of Stroke, Myocardial Infarction and other coronary diseases. In the cardiovascular risk stratification, there was a significant portion of the elderly at risk ranging from medium to very high for cardiovascular diseases. Cardiovascular events in the elderly require multidisciplinary care, and a view focusing on the potential functionality of the person, and one should consider the issue of lifelong education with a view to planning and proposing effective actions aligned to the consolidation of the Unified Health System.

This reality requires the development of strategies and actions aimed at promoting health to the old hypertensive patients group, aiming at their empowerment for self-care, with the aim of informing them of the need and importance of adopting a healthy lifestyle, avoiding possible aggravations. Thus, this study provides contributions for nurses as care workers, with the commitment to bring about changes and transformations through their practice, promoting health and life.

The data collected are worthy of reflection for Nursing research and professional practice, especially regarding the reorganization of the work process, taking a larger dimension in health actions that articulate the knowledge of older people and other professionals while the prevalence of hypertension and its complications increase, requiring more effective health practices. 


\section{Acknowledgements}

To the Family Health Strategy team of the basic unit in which the study was conducted, in particular to the Health Community Agents, for the contributions to the study.

\section{Collaborations}

Queiroz RF and França ALM contributed to the creation, field data collection, analysis, interpretation of data, writing of the article and final approval of the version to be published. Alvarez AM and Erdmann $\mathrm{AL}$ contributed to the creation, interpretation of data, writing of the article and final approval of the version to be published. Pereira CBS contributed to the creation and data collection.

\section{References}

1. Mendes EV. As redes de atenção à saúde. Brasília: Organização Pan-Americana da Saúde; 2011.

2. Clares JWB, Freitas MC, Almeida PC, Galiza FT, Queiroz TA. Perfil de idosos cadastrados numa unidade básica de saúde da família de Fortaleza-CE. Rev Rene. 2011; 12(n esp):988-94.

3. Romero AD, Silva MJ, Silva ARV, Freitas RWJF, Damasceno MMC. Características de uma população de idosos hipertensos atendida numa unidade da família. Rev Rene. 2010; 11(2):72-8.

4. Mendes EV. O cuidado das condições crônicas na atenção primária à saúde: o imperativo da consolidação da estratégia da saúde da família. Brasília: Organização Pan-Americana da Saúde; 2012.

5. Carvalho SR, Gastaldo D. Promoção à saúde e empoderamento: uma reflexão a partir das perspectivas crítico-social e pós-estruturalista. Ciênc Saúde Coletiva. 2008; 13(2):2029-40.

6. Ministério da Saúde (BR). Secretaria de Vigilância em Saúde, Departamento de Análise de Situação de Saúde. Plano de ações estratégicas para o enfrentamento das doenças crônicas não transmissí- veis (DCNT) no Brasil 2011-2022. Brasília: Ministério da Saúde; 2011.

7. Lima VLGP, Campos NZR, Barros MAB, Arruda JM, Zandonadi RCMB, Branco VMC. Politica pública de valorização de paternidade: sistematização e análise de sua implantação no Rio de Janeiro. In: Catrib AMF, Dias MAS, Frota MA. Promoção da saúde no contexto da Estratégia Saúde da Família. Campinas: Saberes; 2011. p. 45-63.

8. Sousa MLT, Lima FA, Sousa RM, Paresque MAC, Carvalho WRL. Por uma nova promoção da saúde com arranjos participativos emancipatório na estratégia saúde da família. In: Catrib AMF, Dias MAS, Frota MA. Promoção da saúde no contexto da estratégia saúde da família. Campinas: Saberes; 2011. p.111-24.

9. Taddeo PS, Gomes KWL, Caprara A, Gomes AMA, Oliveira GC, Moreira TMM. Acesso, prática educativa e empoderamento de pacientes com doenças crônicas. Ciênc Saúde Coletiva. 2012; 17(11):2923-30.

10. Cellard A. A análise documental. In: Poupart J, Deslauriers JP, Grulx LH, Paperriere A, Mayer R, Pires A. A pesquisa qualitativa - enfoques epistemológicos e metodológicos. Petrópolis: Vozes; 2008. p. 295-316.

11. Sociedade Brasileira de Cardiologia, Sociedade Brasileira de Hipertensão. Sociedade Brasileira de Nefrologia. VI Diretrizes Brasileiras de Hipertensão. Arq Bras Cardiol. 2010; 95(1):1-69.

12. Knauth DR, Couto MT, Figueiredo WS. A visão dos profissionais sobre a presença e as demandas dos homens nos serviços de saúde: perspectivas para a análise da implantação da Política Nacional de Atenção Integral à Saúde do Homem. Ciênc Saúde Coletiva. 2012; 17(10):2617-26.

13. Vera RFS, Oliveira JS. Aspectos sociodemográficos que influenciam na adesão ao tratamento anti-hipertensivo. Rev Rene. 2009; 10(3):132-7.

14. Delors J, Al Mufti I, Amagi I, Chung F, Geremek B, Kornhauser, et al. Educação: um tesouro a descobrir. Relatório para a UNESCO da Comissão Internacional sobre a Educação para o século XXI. Brasília: UNESCO; 2010. 
15. Mendonça LBA, Lima FET, Oliveira SKP. Acidente vascular Encefálico como complicação da hipertensão arterial: quais são os fatores intervenientes? Esc Anna Nery. 2012; 16(2):340-6.

16. Brandão AP, Brandão AA, Freitas EV, Magalhães MEC. Hipertensão arterial no idoso. In: Freitas EV, Py L, Cansado FAX, Gorzone ML, Doll J. Tratado de geriatria e gerontologia. 3 a ed. Rio de Janeiro: Guanabara Koogan; 2011. p.436-54.

17. Oliveira CJ, Moreira TMM. Caracterização do tratamento não farmacológico de idosos porta- dores de hipertensão arterial. Rev Rene. 2010; 11(1):76-85.

18. Silva DB, Moreira TMM, Alencar GP, Carvalho IS. Avaliação do risco cardiovascular em idosos hipertensos de uma unidade de saúde de Fortaleza. Rev Tend Enferm. 2009; 1(2):475-80.

19. Bertoletti AR, Costa AGS, Costa FBC, Oliveira ARS, Oliveira CJ, Araújo TL. Diagnóstico de enfermagem falta de adesão em pacientes acompanhados pelo programa de hipertensão arterial. Rev Rene. 2012; 13(3):623-31. 